\title{
PBDEs, PCBs and PCDD/Fs in the sediments from seven major river basins in China: Occurrence, congener profile and spatial tendency
}

\author{
Pu Wang a , Hongtao Shang a, Honghua Li ${ }^{a}$, Yawei Wanga ${ }^{a}$ Yingming Li $^{\text {a }}$, Haidong Zhang ${ }^{\mathrm{a}}$, \\ Qinghua Zhang ${ }^{\mathrm{a}, \mathrm{b}, *}$, Yong Liang ${ }^{\mathrm{b}}$, Guibin Jiang ${ }^{\mathrm{a}}$
}

${ }^{a}$ State Key Laboratory of Environmental Chemistry and Ecotoxicology, Research Center for Eco-Environmental Sciences, Chinese Academy of Sciences, Beijing, 100085, China

${ }^{\mathrm{b}}$ Institute of Environment and Health, Jianghan University, Wuhan, 430056, China

\section{H I G H L I G H T S}

- PBDEs, PCBs and PCDD/Fs were extensively investigated in the sediment samples collected from seven major river basins around China.

- The concentrations showed wide variations among different river basins.

- The spatial analysis identified a decreasing trend of these POPs from south to north China, consistent with regional industrialization.

\section{A R T I C L E I N F O}

\section{Article history:}

Received 29 April 2015

Received in revised form 11 August 2015

Accepted 12 August 2015

Available online 4 September 2015

Handling editor: Myrto Petreas

Keywords:

PBDEs

PCBs

PCDD/Fs

Sediment

Chinese river basin

\section{G R A P H I C A L A B S T R A C T}

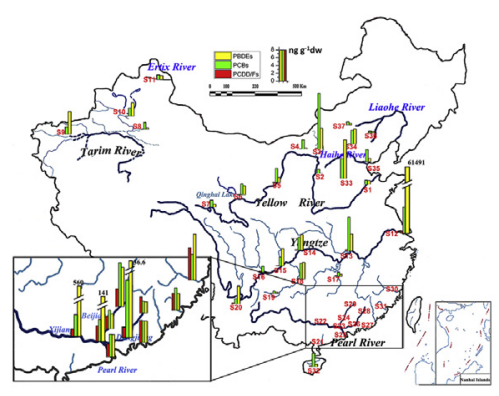

A B S T R A C T

Polybrominated diphenyl ethers (PBDEs), polychlorinated biphenyls (PCBs) and polychlorinated dibenzop-dioxins/dibenzofurans (PCDD/Fs) were extensively investigated in the sediment samples collected from seven major river basins around China. The concentrations were in the range of $0.05-6.15 \times 10^{4} \mathrm{ng} \mathrm{g}^{-1}$ dry weight (dw), 0.29-21.7 $\mathrm{ng} \mathrm{g}^{-1} \mathrm{dw}$ and 0.01-6.49 $\mathrm{ng} \mathrm{g}^{-1} \mathrm{dw}$ for PBDEs, PCBs and PCDD/Fs, respectively. The concentrations showed wide variations among different river basins, while the congener profiles in all the sediments were generally characterized by only a few compounds, such as BDE-209, -99 and $-47, C B-11$ and -28, OCDD and OCDF, etc. The spatial analysis identified a decreasing trend of these persistent organic pollutants (POPs) from south to north China, consistent with regional industrialization. However, relatively higher level of POPs was also observed in the upstream of Yellow River Basin. The present study gives insight into the spatial occurrence of the three POPs in the major river basins in China.

(c) 2015 Elsevier Ltd. All rights reserved.

\section{Introduction}

In the recent decades, persistent organic pollutants (POPs) received great attention due to their potential adverse health effects on wildlife and humans. As three typical POPs substances, poly-

\footnotetext{
* Corresponding author. State Key Laboratory of Environmental Chemistry and Ecotoxicology, Research Center for Eco-Environmental Sciences, Chinese Academy of Sciences, China.

E-mail address: qhzhang@rcees.ac.cn (Q. Zhang).
}

brominated diphenyl ethers (PBDEs), polychlorinated biphenyls (PCBs) and polychlorinated dibenzo-p-dioxins/dibenzofurans ( $P C D D / F s)$ have been extensively studied involving their bioaccumulation, persistence in the environment and toxic effects on the organisms.

PBDEs and PCBs were commercially produced for wide industrial use. As a major brominated flame retardant (BFR), PBDEs were produced globally with approximately 67,400 metric tons in $1999,37 \%$ of which was from Asia (BSEF, 2000). The domestic demand of BFRs has increased at a rate of $8 \%$ per year in the early 
2000s in China, and deca-BDE was the major product of BFRs (Mai et al., 2005). Although the components of the penta-BDE and octaBDE commercial mixtures have been banned since 2009 under the Stockholm Convention, deca-BDE was still widely used with global sales of 7500-10,000 metric tons in 2011 (BSEF, 2012). PCBs were also manufactured with approximately 10,000 tons in China before it was banned in the 1970s (Fu et al., 2003). Ba contrast, PCDD/Fs are unintentionally discharged during some industrial processes (e.g., incineration of chlorine-containing substances and chlorine bleaching of paper) and from natural sources (e.g., volcanoes and forest fires). The total release of dioxin from all sources in China in 2004 was estimated at $10.2 \mathrm{~kg}$ international toxic equivalent (ITEQ) (China's NIP, 2007).

In China seven major water systems, including Yellow River, Yangtze River, Pearl River, Tarim River, Ertix River, Haihe River, and Liaohe River, go across 26 provinces with a total drainage area of 3.78 million $\mathrm{km}^{2}$, and cover approximately $40 \%$ of the territory of China. Most major cities in China are located along the rivers, and water pollution gets increasingly severe in tandem with rapid economic growth. Many BFRs production factories, metallurgical plants, sewage treatment plants, paper mills, etc. are situated close to these rivers, resulting in the release of PBDEs, PCBs and PCDD/Fs into the aqueous system. Some regional studies have revealed the POPs pollution in the aquatic systems around China, including water (Guan et al., 2007; Liu et al., 2008), fish (Han et al., 2007; Wei et al., 2011), sediment (Chen et al., 2006; Li et al., 2014; Shen et al., 2006; Sun et al., 2005), etc. The results suggested occurrence of bioaccumulation and biomagnification of POPs in aquatic biotas, which may threaten human health, especially for the local inhabitants.

The most investigations in sediment paid attention to the specified areas around large cities (Chen et al., 2006; Zhang et al., 2010, 2009). Less is known about POPs in more rural areas along these rivers. The aim of the present study was to comprehensively investigate PBDEs, PCBs and PCDD/Fs in the whole basins of seven rivers (Yellow River, Yangtze River, Pearl River, Haihe River, Tarim River, Ertix River, and Liaohe River), the results could gain insight into the geographical distribution of these three POPs in the river basins around China, which also benefits for the identification of potential source in the local area.

\section{Materials and methods}

\subsection{Sample collection}

The sampling details, preservation and pretreatment of the sediment samples were described in our previous work (Li et al., 2013). A total of 261 sediments were obtained and then combined to 37 composite samples according to the principle of proximity and same water source. These composite samples reflected the characteristics of general pollution of Yellow River Basin, Tarim River basin, Ertix River, Yangtze River Basin, Pearl River Basin, Haihe River Basin and Liaohe River Basin.

\subsection{Sample extraction and analysis}

Sample extraction, cleanup and chemical analysis followed our previous method with some minor modifications (Liu et al., 2006). Detailed procedures were given in the Supplementary material. High-resolution gas chromatography/high-resolution mass spectrometry (HRGC/HRMS) was employed for quantification of all the targets except BDE-209 of which the measurement was performed on a gas chromatography/low-resolution mass spectrometry (GC/LRMS).

\subsection{Quality assurance and quality control $(Q A / Q C)$}

All the performance criteria required for the analysis of PBDEs, PCBs and PCDD/Fs followed US EPA methods (1614, 1668A and 1613B). ${ }^{13} \mathrm{C}$-labeled surrogated standards (PBDE-LCS $\left({ }^{13} \mathrm{C}_{12}\right.$-BDE-47, -99 and -153), 68A-LCS and 1613-LCS) were spiked in the sample for qualification and quantification, and ${ }^{13} \mathrm{C}$-labeled injection standards (EPA 68A-IS and 1613-IS) were added for recovery calculation. The recoveries of the surrogate standards ranged from $50.2 \pm 15.0 \%, 76.7 \pm 25.2 \%$ and $49.2 \pm 13.6 \%$ for PBDEs, PCBs and PCDD/Fs, respectively, which all met the requirements of US EPA methods 1614, 1668A and 1613B. Limit of detection (LOD) in the sample was defined as the signal to noise $(\mathrm{S} / \mathrm{N})$ ratio $=3$. The LOD values were in the range of $0.08-53.4 \mathrm{pg} \mathrm{g}^{-1}$ for PBDEs with a range of $0.20-40.5 \mathrm{pg} \mathrm{g}^{-1}$ for BDE-209, 0.01-0.82 $\mathrm{pg} \mathrm{g}^{-1}$ for PCBs and $0.04-8.40 \mathrm{pg} \mathrm{g}^{-1}$ for PCDD/Fs. Laboratory blanks were analyzed with samples quality control at set intervals, and there was no evident detection of target compounds in blanks.

\section{Results and discussion}

\subsection{The overall concentrations and distribution}

The concentrations of PBDEs, PCBs and PCDD/Fs in the sediments from seven river basins in China were shown in Fig. 1 and the Supplementary Material (Tables S1-S4). The sum concentrations of PBDEs ( $\Sigma_{14}$ PBDEs) ranged between $0.05 \mathrm{ng} \mathrm{g}^{-1}$ dry weight (dw) and 61,500 $\mathrm{ng} \mathrm{g}^{-1} \mathrm{dw}$ with mean and medium values of $1680 \mathrm{ng} \mathrm{g}^{-1} \mathrm{dw}$ and $2.92 \mathrm{ng} \mathrm{g}^{-1} \mathrm{dw}$, respectively. Extremely high values were observed in the sites $\mathrm{S} 12\left(61,500 \mathrm{ng} \mathrm{g}^{-1}\right)$ in Yangtze River Delta, S22 (559 $\left.\mathrm{ng} \mathrm{g}^{-1}\right)$ and S23 (141 $\left.\mathrm{ng} \mathrm{g}^{-1}\right)$ in Pearl River Basin. These results were higher than those observed in Lake Maggiore in Europe (0.06-27 ng g ${ }^{-1} \mathrm{dw}$, Vives et al., 2007) and Great Lake area (Song et al., 2005a, 2005b, 2004). PBDE levels were relatively higher than the other two contaminants in Yangtze River Delta, Pearl River Basin and Haihe River Basin, where the developed industries and commerce were more aggregated. Geographically, the PBDE levels varied widely among the different river valleys and were generally higher in southern China than the northern areas (Fig. 2), which is in agreement with the observation for hexabromocyclododecane (HBCD) in river sediments in our previous work (Li et al., 2013).

For PCBs, they were detected in all the samples and the total concentrations ranged from $0.29 \mathrm{ng} \mathrm{g}^{-1} \mathrm{dw}$ to $21.7 \mathrm{ng} \mathrm{g}^{-1} \mathrm{dw}$ with a mean value of $4.40 \mathrm{ng} \mathrm{g}^{-1} \mathrm{dw}$. They were generally consistent with the data in China reviewed by Xing et al. (2005). Compared with the results in the other countries, they were also in agreement with those in Lake Maggiore in Europe $\left(0.3-38 \mathrm{ng} \mathrm{g}^{-1} \mathrm{dw}\right.$, Vives et al., 2007) and Saginaw River Watershed in Michigan, USA (0.1-1520 ng g $^{-1}$ dw, Kannan et al., 2008). Similar to PBDEs, higher levels of PCBs were observed in southern China (Fig. 2). Especially in Pearl River Basin, the mean concentration was 4 times higher than that in northern China.

For PCDD/Fs, the concentrations (sum of tetra-to octahomologues) were in the range of $0.01-6.49 \mathrm{ng} \mathrm{g}^{-1} \mathrm{dw}$ with a mean value of $1.09 \mathrm{ng} \mathrm{g}^{-1} \mathrm{dw}$. These were consistent with the studies in some foreign regions, e.g., Lake Maggiore in Europe $\left(0.0035-2.21 \mathrm{ng} \mathrm{g}^{-1}\right.$, Vives et al., 2007) and Korean rivers (0.00088-0.369 ng g $\mathrm{g}^{-1}$, Ryoo et al., 2005). They were also comparable to or even lower than those in the Great Lake area (0.03$10 \mathrm{ng} \mathrm{g}^{-1} \mathrm{dw}$ in Lakes Erie and Ontario, Shen et al., 2008; 0.003$18 \mathrm{ng} \mathrm{g}^{-1} \mathrm{dw}$ in Lakes Superior and Huron, Shen et al., 2009b). As exhibited in Fig. 2, spatial distribution of PCDD/Fs was comparable to those of PBDEs and PCBs with generally higher contamination levels in south China. The concentrations in Pearl River Basin were even 20 times higher than those in the northern river basins. This 


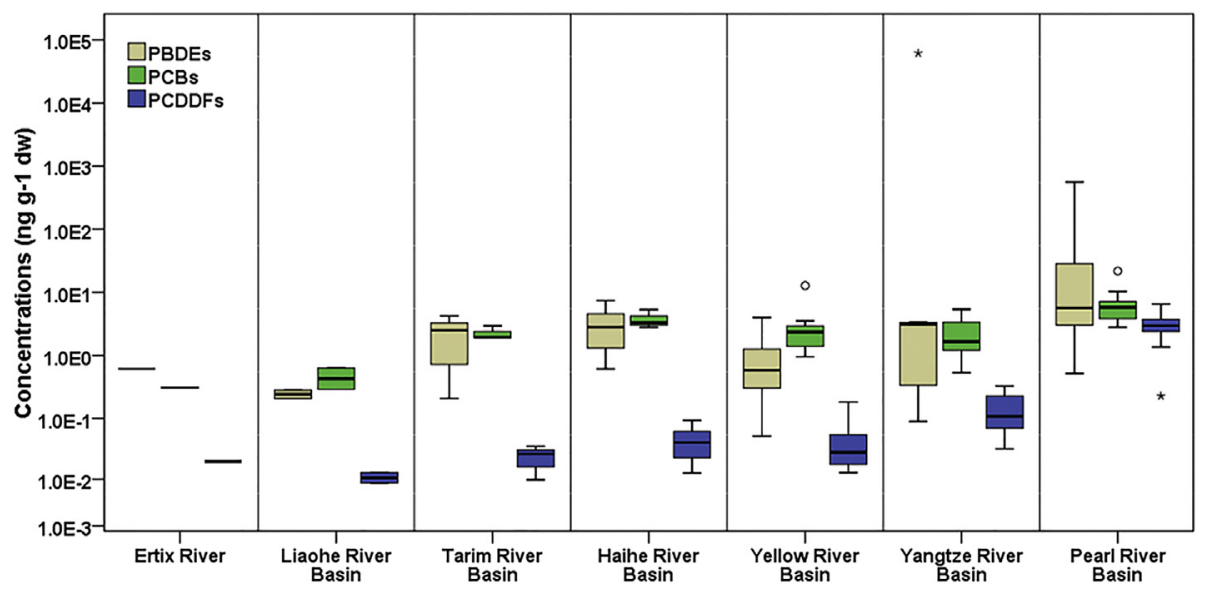

Fig. 1. The overall concentrations of PBDEs, PCBs and PCDD/Fs in the sediments from seven river basins in China.

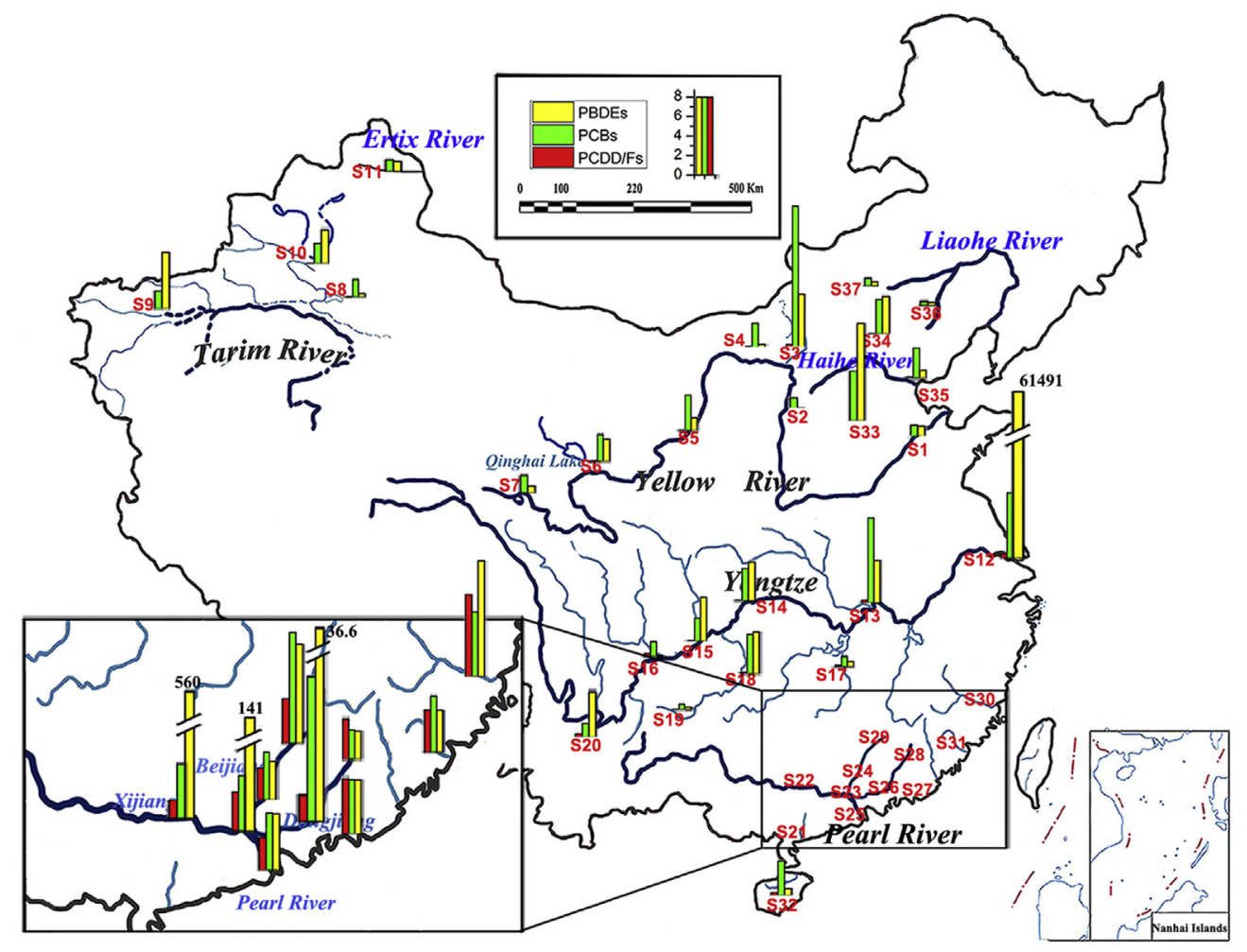

Fig. 2. Spatial distribution of PBDEs, PCBs and PCDD/Fs concentrations in the sediments (ng $\mathrm{g}^{-1} \mathrm{dw}$ ).

tendency was also in accordance with the observation by Zheng et al. (2008).

WHO-TEQ values of PCDD/Fs and PCBs were calculated based on $\mathrm{WHO}_{1998}$-TEFs for comparative purposes with previous study. The total TEQ (sum of PCDD/Fs and PCBs) values were in the range of $0.003-4.27 \mathrm{pg}^{\mathrm{TEQ}} \mathrm{g}^{-1} \mathrm{dw}$ with a mean value of $0.58 \mathrm{pg}$ TEQ $\mathrm{g}^{-1} \mathrm{dw}$ (Tables S1-S4). The top levels were found in Pearl River Basin with a mean value of $1.46 \mathrm{pg}^{\mathrm{TEQ}} \mathrm{g}^{-1} \mathrm{dw}$, followed by $0.14 \mathrm{pg}$ TEQ $\mathrm{g}^{-1} \mathrm{dw}$ in Yangtze River Delta. However, they were still lower than those from Lake Maggiore in Europe (0.1-32 pg TEQ $\mathrm{g}^{-1} \mathrm{dw}$, Vives et al., 2007), Korean (0.0723.9 pg TEQ $\mathrm{g}^{-1} \mathrm{dw}$, Ryoo et al., 2005) and the Great Lake area (Shen et al., 2009b, 2008). The ratios of PCDD/F-TEQ versus PCB-TEQ were higher than 1 in the most samples, especially in Yangtze and Pearl River Basins, revealing a great contribution con- tamination of $\mathrm{PCDD} / \mathrm{Fs}$ in these areas. According to the interim sediment quality guidelines (ISQGs) of USA (US EPA, 1993) and Canada (CCME, 2002), in which the prescribed values were 2.50 and $0.85 \mathrm{pg} \mathrm{TEQ}^{-1} \mathrm{dw}$, the total TEQs of 8 samples (S3, S22-S24, S26 and S28-S30) were higher than the value in ISQGs of Canada and two of them (S23 and S24) were more than that in USA guidelines.

\subsection{Spatial distribution in the main river basins}

\subsubsection{Yellow River basin}

The overall concentrations of POPs showed a generally decreasing tendency from the upper to the lower reaches (Fig. 2). This could be attributed to dilution effects with more abundant sand and lower total organic carbon (TOC) contents in the lower reaches 
(Table S1). In the Yellow River Estuary S1, PBDEs level was comparable to the report in Bohai sea (Pan et al., 2010a). However, PCBs showed higher concentrations than those reported by Hui et al. (2009) and Pan et al. (2010b) in the same region and Bohai sea (Pan et al., 2010a), while it was still lower than the results reported by He et al. (2006b). The concentration of PCDD/Fs was lower than many other results (Hui et al., 2009; Pan et al., 2010b). The exceptionally higher level of POPs was observed in the reservoir (S3) which is far away from the main stream of Yellow River. This could be due to a short distance from the city (Baotou) which is an important industrial city focusing on metallurgy, rare-earth (RE), manufacturing and chemicals in Inner Mongolia Province. In Ningxia of the Yellow River Valley (S5), several sewage treatment plants were found around the sampling site, which might be responsible for the higher concentrations of PCBs and PBDEs. Moreover, high concentrations of contaminants (PBDEs, $1.69 \mathrm{ng} \mathrm{g}^{-1} \mathrm{dw}$; PCBs, $2.44 \mathrm{ng} \mathrm{g}^{-1} \mathrm{dw}$; PCDD/Fs, $0.04 \mathrm{ng} \mathrm{g}^{-1} \mathrm{dw}$ ) were observed in the sample from Qinghai Lake S6 which is a famous national protected site of China with no industrial sites and potential emission sources. Considering that "Bird Islands" is located at the tip of the peninsula on the western side of the lake and a large number of birds inhibited, birds migration may be the main pathway for POPs transport to this area (Blais et al., 2005).

\subsubsection{Yangtze River Basin}

Compared to Yellow River Basin, relatively higher level of POPs was observed downstream of Yangtze River Basin (S12, S13) (Table S2). Especially in Yangtze River Delta (S12), one of the most developed regions and important harbors in China, the levels of PBDEs, PCBs and PCDD/Fs were up to ten thousand times higher than the lowest values. The higher levels of POPs in the Lower Reaches were also reviewed by Floehr et al. (2013). PCDD/F and PCB concentrations were generally comparable to the previous results in the lower reaches areas of Yangtze River (Nie et al., 2013; Shen et al., 2006; Sun et al., 2005; Yang et al., 2009). Unlikely, PBDE concentration in Yangtze River Delta S12 was much higher than the observation by Chen et al. (2006) in the intertidal zone of the Yangtze River Delta and Li et al. (2014) in the estuary and East China Sea. This could be attributed to the different sampling sites and reported congeners. Li et al. (2014) reported the determination of 13 BDE congeners without BDE-209, while extremely high level of BDE-209 was observed in the composite sample in our study (99.9\% of $\Sigma_{14}$ PBDEs).

\subsubsection{Pearl River basin}

Distinctively, POPs was at a constantly high level along the river (Table S3). The highest PBDE concentration was detected in Xijiang River S22 (559 $\mathrm{ng} \mathrm{g}^{-1} \mathrm{dw}$ ), followed by S23 (141 $\mathrm{ng} \mathrm{g}^{-1} \mathrm{dw}$ ) which is located in the river confluence reach of Beijiang, Xijiang and Pearl River. PCBs concentration was up to $21.7 \mathrm{ng} \mathrm{g}^{-1} \mathrm{dw}$ in S26 in Dongjiang River, one tributary of Pearl River. Nevertheless, the highest PCDD/F concentration was measured in site S21 in Guangdong Province (6.49 $\mathrm{ng} \mathrm{g}^{-1} \mathrm{dw}$ ), followed by site $\mathrm{S} 30$ (6.23 $\mathrm{ng} \mathrm{g}^{-1} \mathrm{dw}$ ) in Fujian Province. In the Pearl River Delta (S25), PBDE concentrations were much higher than those reported by Chen et al. (2009) and Mai et al. (2005) in Beijiang and Xijiang River, but lower than the results in Dongjiang and Zhujiang River (Mai et al., 2005). Whereas, the PCBs concentration (6.61 ng $\mathrm{g}^{-1} \mathrm{dw}$ ) was lower than the observation by Nie et al. (2005) and Wang et al. (2011). For PCDD/Fs, the concentration (2.44 $\mathrm{ng} \mathrm{g}^{-1} \mathrm{dw}$ ) was comparable to the previous reports (Zhang et al., 2009; Zheng et al., 2001), but the TEQ value (0.27 $\left.\mathrm{pg} \mathrm{g}^{-1} \mathrm{dw}\right)$ was much lower.

\subsubsection{Other river basins}

In general, PBDEs and PCBs showed relatively higher levels in Haihe River (Table S4), where developed industries and commerce were more aggregated. The three contaminants were changed slightly in Tarim River Basin and the concentrations fell into the moderate pollution level compared with those in other rivers of north China (Table S1). Even in Liaohe River, they were at much lower level compared to the previous studies (Liu et al., 2007; Zhang et al., 2010).

\subsection{The congener profiles}

For PBDEs, BDE-209 was detected in all the samples of Yangtze River basin and Pearl River basin (Fig. S1 (A)). The concentration was up to $61,500 \mathrm{ng} \mathrm{g}^{-1} \mathrm{dw}$ in Yangtze River Delta. As the most abundant congener, BDE-209 contributed to more than $60 \%$ of $\Sigma_{14}$ PBDEs except for the site S3 in Yellow River basin, where BDE209 was not detected. Subsequently, BDE-47 and 99 contributed to $30.5 \%$ and $23.2 \%$ (median value) of $\Sigma_{13}$ PBDEs (without BDE209), respectively. The composition patterns of PBDEs in the samples from middle and lower reaches of Yangtze, Pearl and Liaohe River Basins were consistent with the observations in Yangtze River Delta (Chen et al., 2006) and Pearl River (Chen et al., 2009), where the levels of BDE-47 were higher than BDE-99. However, in most of the other sites including Yellow and Tarim River Basins, BDE99 was more abundant than BDE-47, which corroborated the studies in other countries (Lacorte et al., 2006; Rayne et al., 2003). The total contributions of BDE-153, -154 and -183 , the major components of technical octa-BDE mixtures (Eljarrat et al., 2005), were low with a median percentage of $11.3 \%$ except for S12 in Yangtze River Estuary, where the proportion reached to $71.1 \%$. On the whole, the proportion of lower-brominated BDEs in sediments was relatively higher in most samples besides BDE-209, which may be due to the application of different commercial PBDE formula (Chen et al., 2006) and potential degradation of the higherbrominated BDEs (Gerecke et al., 2005; He et al., 2006a).

Concerning PCBs, the indicator PCBs were the dominants, contributing to more than $80 \%$ of $\Sigma_{18}$ PCBs (sum of 12 dioxin-like PCBs (dl-PCBs) and 6 indicator congeners) and $>25 \%$ of the total PCBs. The most abundant congener was CB-28 (21.3-83.7\% of $\left.\Sigma_{18} \mathrm{PCB}\right)$ followed by CB-52, $-101,-138$ and -153 (Fig. S1 (B)), which was in agreement with the pattern in sediments of Liaohe River in China (Zhang et al., 2010), but different with the other studies, such as Istanbul strait, and the Wuhan reach of the Yangtze River (Okay et al., 2009; Yang et al., 2009). For dl-PCBs, CB-105 and -118 were detected in all the samples and represented $48.1-87.8 \%$ of the $\mathrm{dl}-$ $\mathrm{PCBs}$ concentrations. The most toxic congener $\mathrm{CB}-126$ ranged from not-detected (ND) to $3.4 \%$ of dl-PCBs, with a detection rate of $70 \%$.

3, 3'-dichlorobiphenyl (CB-11), a non-Aroclor PCB congener, was also ubiquitously detected in the present study (Fig. S2), ranging from 0.04 to $2.57 \mathrm{ng} \mathrm{g}^{-1} \mathrm{dw}$. As a predominant congener, the contribution of CB-11 to total PCBs accounted for $19.2 \%$ (mean value). The spatial distribution suggested a higher level of CB-11 in Pearl River areas, while no significant differences were observed among the other river basins ( $p>0.05$, one-way ANOVA). Rodenburg et al. (2010) employed the ratio of CB-11 to CB-4 to investigate the primary source of $C B-11$, if the ratio was less than $1, C B-11$ was probably raised from dechlorination of higher-chlorinated $\mathrm{PCBs}$. In the present study, the ratios between $\mathrm{CB}-11$ and total di-CBs were calculated, which were more than 0.5 except for S12. This indicated that the ratios between $C B-11$ and $C B-4$ were greater than 1 , and the dechlorination of higher-chlorinated PCBs could not be the main source of $\mathrm{CB}-11$ in the Chinese sediments.

For PCDD/Fs, higher-chlorinated congeners were more frequently detected in the samples, such as OCDD, OCDF, 1,2,3,4,6,7,8- 
HpCDD and 1,2,3,4,6,7,8-HpCDF (Fig. S1 (C)). Component analysis indicated that OCDD and OCDF contributed to $75.5 \%$ and $8.5 \%$ of $\Sigma_{17} \mathrm{PCDD} / \mathrm{Fs}$, followed by $1,2,3,4,6,7,8-\mathrm{HpCDD}$ (2.5\%). The most toxic congeners (2,3,7,8-TCDD and 1,2,3,7,8-PeCDD) were only detected at a relatively low levels in S23 and S28, which both were located in Pearl River Basin. 1,2,3,7,8,9-HxCDF was not detected in any samples. The ratios of PCDDs against PCDFs were much higher than 1 (>30) in the Pearl River Basin and midstream of Yangtze River Basin, while they were relatively low in the other sites (0.1411.8), especially in Yellow River and Tarim River basin (most ratios <1). This may suggest different emission sources in south and north China. In Pearl River and midstream of Yangtze River
Basins, PCDD/Fs were characterized by much higher OCDD and HpCDD, suggesting a major PCDD source associated with sodium pentachlorophenate (Na-PCP), polychlorophenol (PCP) or pulp mills (Chen et al., 2012; Nie et al., 2013; Rappe, 1993; Zheng et al., 2008). As reviewed by Zheng et al. (2008), Na-PCP was extensively used as an Oncomelania killer (O. hupensis) to control Schistosomiasis disease in south China (e.g., Dongting Lake area in midstream of Yangtze River Basin, Xiangjiang region in Pearl Delta region), which could be the most important source of PCDD/Fs in these areas. Additionally, the patterns in Pearl River Delta showed a higher abundance of PCDFs, which is similar with the observations in the soil from Taizhou and Guiyu (Leung et al., 2007; Shen et al.,
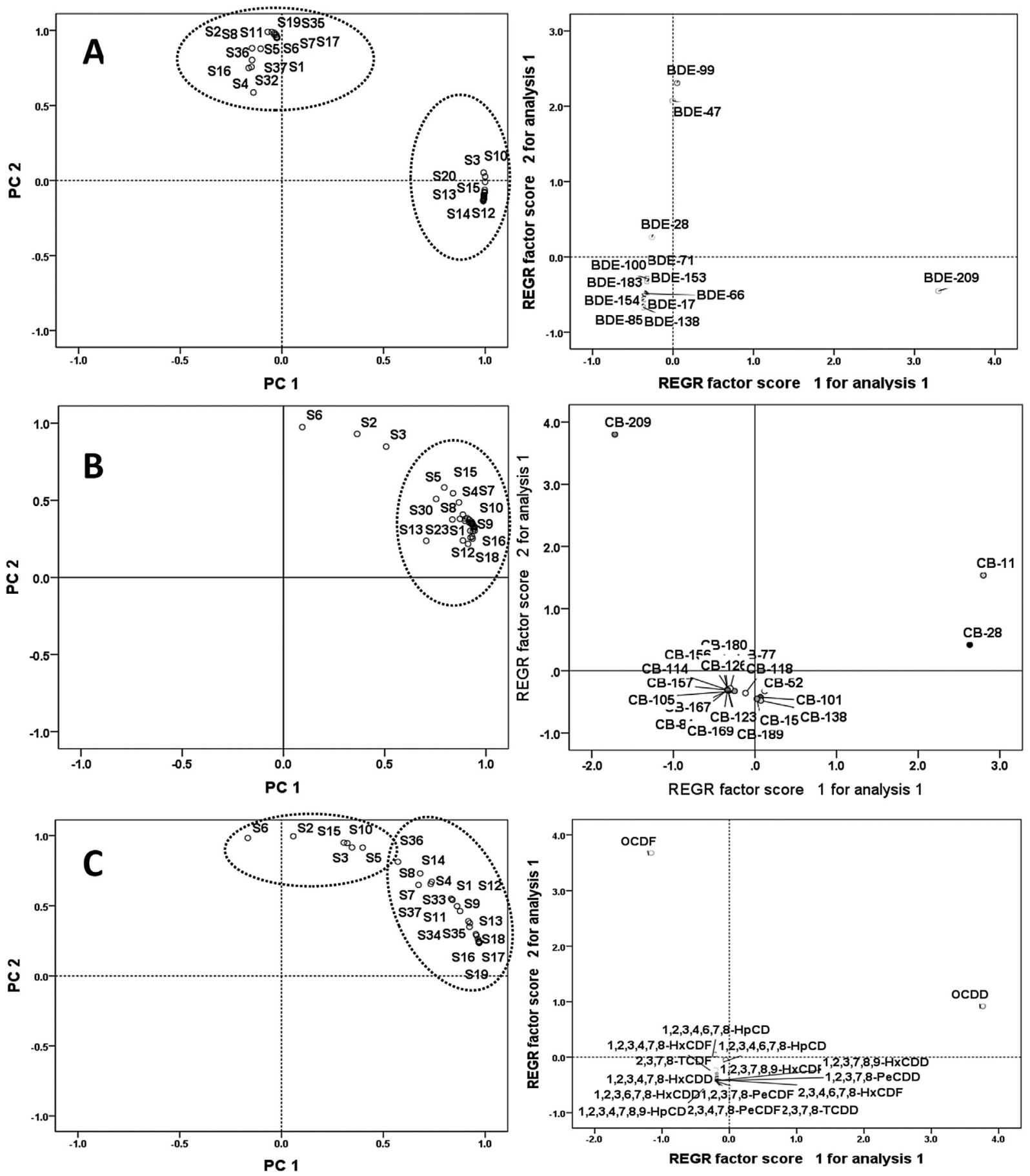

Fig. 3. PCA score plot and REGR factor score plot for PBDEs (A), PCBs (B) and PCDD/Fs (C) in sediment samples from seven different river basins in China. 
2009a), two notorious E-waste recycling areas in south China. It suggested PCDD/Fs in Pearl River Delta could also be attributed to the E-waste recycling activities with primitive and crude techniques (e.g., burning of electrical cables and printed circuit boards). However, in north China, especially the Yellow River Basin, the ratios of PCDDs/PCDFs were generally close to or even lower than 1 , suggesting a near constant/universal PCDF source referring to steelworks, metal refinery factories, coal and oil industries, domestic cooking and heating, municipal and medical waste incineration, as well as vehicle exhaust emissions (Liu and Zheng, 2013; Zheng et al., 2008).

\subsection{PCA analysis}

Principal component analysis (PCA) was employed for further assessment of POPs in the sediment from the seven river basins. The score and 2D plot of REGR factor for PBDEs, PCBs and PCDD/Fs were shown in Fig. 3.

As exhibited in Fig. 3(A), 92.3\% of the PBDE variation could be explained by PC1 $(59.0 \%)$ and PC2 (33.3\%) (Eigenvalue $>1$ ). All the samples had positive factor scores on PC1 and PC2. It is distinctive that the most samples from Yangtze River basin (S12-S15, S18, and S20), Pearl River basin (S21-S31) and Haihe River (S33, S34) were charactered by PC1 with a signature of BDE-209. These sites were located in east and south China with more developed industry and commerce, which suggested that technical deca-PBDE mixture was extensively used in these regions. In addition, the sites in Yellow River basin (S3) and Trim River basin (S10) nearby the cities with heavy industry also had higher loading values of PC1, indicating the influence of commercial deca-BDE mixture on the local environment. On the other hand, the majority of samples from Yellow River basin, Tarim River basin, and Liaohe River Basin had higher loading values of PC2 in the component plot and featured by BDE47 and -99 , the major congeners of the penta-formulation of PBDEs. Considering that BDE-209 was still the dominant congener in these samples, technical penta-BDE mixtures might have been ubiquitously produced and/or used in most cities in north China other than the deca-BDE commercial mixture.

For PCBs, $94.7 \%$ of the PCB variation could be explained by PC1 and PC2 (Eigenvalue $>1$ ) (Fig. 3(B)). All the samples had a similar contamination profile due to high score in $\mathrm{PC} 1$ in positive direction except for S2, S3 and S6, manifesting the dominance of CB-11 and -28 in the most sites. The three outliers were all located in Yellow River Basin, charactered by CB-209. As demonstrated previously, Qinghai Lake (S6) is famous for "Bird Islands" without industrial sites and emission sources. Bird migration may lead to historical accumulation of high-chlorinated CBs in this area. However, CB-209 was comprised $<1 \%$ of the $\Sigma$ PCBs in most of the commercial Aroclors except Aroclor 1268 (Kannan et al., 1997). Rowe et al. (2007) observed higher level of CB-209 in the suspended solids of Delaware River, and one possible source is a titanium dioxide purification plant that is located on the lower Delaware. In the present study, field investigation indicated S2 and S3 sites could be affected by some industrial cities, e.g., Lvliang City, Yulin City and Baotou City, where coal chemical industry, metallurgy, rareearth (RE), manufacturing were extensively developed. It probably contributes to the feature of CB-209 in these sampling sites.

Regarding PCDD/Fs, the first two components (PC1, PC2) (Eigenvalue $>1$ ) could explain $85.8 \%$ and $13.3 \%$ of the total variance, respectively (Fig. 3(C)). OCDD dominated all the sampling sites in south China (except S15), while OCDF was the main influence factor for most sites in north China (e.g., S2, S3, S5, S6, and S10). This is exactly verified our hypothesis on the disparity of PCDD/Fs emission source between south and north China as demonstrated above.

\subsection{The effect of total organic carbon (TOC) contents}

The TOC is considered an important factor to influence the distribution of organic contaminants (Chen et al., 2006; Cornelissen et al., 2005). The mean TOC content was $2.03 \pm 1.00 \%$ in the sediments in this study, which was higher than some other studies in Pearl River Delta (1.15 $\pm 0.32 \%$, Mai et al., 2005; 0.55-2.38\%, Chen et al., 2012) and Yangtze River Delta ( $0.36 \pm 0.17 \%$; Chen et al., 2006; 0.12-1.25\%, Nie et al., 2013). Correlation analysis showed that a positive dependence was only obtained for PCB concentrations against TOC contents with a low Pearson correlation coefficient $(0.348, p=0.035)$. The generally poor correlation between TOCs and POPs in the sediment was commonly observed in many previous studies (Chen et al., 2009, 2006; Mai et al., 2005), indicating less influence of TOC contents to the distribution of POPs in the river sediment. Similar patterns were observed when sites were compared using TOC normalized concentrations except for S36 in Liaohe Basin and S32 in Pearl River Basin (Fig. S3). This could be attributed to relatively lower TOC contents in these two samples (0.04\% in S36 and $0.61 \%$ in S32).

\section{Conclusions}

PBDEs, PCBs and PCDD/Fs were comprehensively investigated in the sediment from Chinese major river basins. All the three POPs substances were detected in the samples, suggesting their ubiquities in the Chinese rivers. The spatial analysis identified a decreasing trend of POPs levels from the south to north China. The contamination in Pearl River Basin was more serious compared to the other river basins, followed by Yangtze River Basin. The congener profiles demonstrated an evident influence of the industry and commerce development on the POPs distribution. This reminds us to pay more attention to environmental protection along with the economic development since that accumulated POPs substances may raise potential risk to ecosystem especially human health.

\section{Acknowledgements}

This research has been supported by National Natural Science Foundation of China (NO. 21477156, 21277165, 21307148), Chinese Academy of Sciences (XDB14010100 and YSW2013B01) and the National Water Pollution Control Program (No. 2012ZX07203-006-08). We all thank for the assistance in sample collection from China Institute of Water Resources and Hydropower Research.

\section{Appendix A. Supplementary data}

Supplementary data related to this article can be found at http://dx.doi.org/10.1016/j.chemosphere.2015.08.045.

\section{References}

Blais, J.M., Kimpe, L.E., McMahon, D., Keatley, B.E., Mattory, M.L., Douglas, M.S.V., Smol, J.P., 2005. Arctic seabirds transport marine-derived contaminants. Science 309, 445-445.

BSEF, 2012. European Annual Progress Report 2011. The Voluntary Emissions Control Action Programme Available: http://www.bsef.com/uploads/Documents/ documents/VECAP_report_light(1).pdf.

BSEF, 2000. An Introduction to Bromine Brussels: Bromine Science and Environmental Forum Available: http://www.bsefsite.com/docs/bromine.pdf (accessed 20.11.03).

CCME, 2002. Canadian Environmental Quality Guidelines for Polychlorinated Dibenzo-p-dioxins and Polychlorinated Dibenzofurans (PCDD/Fs) Available http: //ceqg-rcqe.ccme.ca/download/en/245.

China's NIP, 2007. National Implementation Plan for the Stockholm Convention on Persistent Organic Pollutants Available: http://www.pops.int/documents/ implementation/nips/submissions/China_NIP_En.pdf. 
Chen, L.G., Huang, Y.M., Peng, X.C., Xu, Z.C., Zhang, S.K., Ren, M.Z., Ye, Z.X. Wang, X.H., 2009. PBDEs in sediments of the Beijiang River, China: levels, distribution, and influence of total organic carbon. Chemosphere 76, 226-231.

Chen, S.J., Gao, X.J., Mai, B.X., Chen, Z.M., Luo, X.J., Sheng, G.Y., Fu, J.M., Zeng, E.Y., 2006. Polybrominated diphenyl ethers in surface sediments of the Yangtze River Delta: levels, distribution and potential hydrodynamic influence. Environ. Pollut. 144, 951-957.

Chen, Z.L., Yang, B., Mengoni, A., Dong, J.H., Peng, X.C., 2012. Distribution patterns of polychlorinated dibenzo-p-dioxins and polychlorinated dibenzofurans in sediments of the Xiangjiang River, China. Environ. Monit. Assess. 184, 7083-7092.

Cornelissen, G., Gustafsson, O., Bucheli, T.D., Jonker, M.T.O., Koelmans, A.A., Van Noort, P.C.M., 2005. Extensive sorption of organic compounds to black carbon, coal, and kerogen in sediments and soils: mechanisms and consequences for distribution, bioaccumulation, and biodegradation. Environ. Sci. Technol. 39, 6881-6895.

Eljarrat, E., De La Cal, A., Larrazabal, D., Fabrellas, B., Fernandez-Alba, A.R., Borrull, F. Marce, R.M., Barcelo, D., 2005. Occurrence of polybrominated diphenylethers, polychlorinated dibenzo-p-dioxins, dibenzofurans and biphenyls in coastal sediments from Spain. Environ. Pollut. 136, 493-501.

Floehr, T., Xiao, H., Scholz-Starke, B., Wu, L., Hou, J., Yin, D., Zhang, X., Ji, R., Yuan, X. Ottermanns, R., Roß-Nickoll, M., Schäffer, A., Hollert, H., 2013. Solution by dilution? - A review on the pollution status of the Yangtze River. Environ. Sci. Pollut. Res. Int. 20, 6934-6971.

Fu, J.M., Mai, B.X., Sheng, G.Y., Zhang, G., Wang, X.M., Peng, P.A., Xiao, X.M., Ran, R., Cheng, F.Z., Peng, X.Z., Wang, Z.S., Tang, U.W., 2003. Persistent organic pollutants in environment of the Pearl River Delta, China: an overview. Chemosphere 52 , 1411-1422.

Gerecke, A.C., Hartmann, P.C., Heeb, N.V., Kohler, H.P., Giger, W., Schmid, P., Zennegg, M., Kohler, M., 2005. Anaerobic degradation of decabromodiphenyl ether. Environ. Sci. Technol. 39, 1078-1083.

Guan, Y.F., Wang J.Z., Ni, H.G., Luo, X.J., Mai, B.X., Zeng, E.Y., 2007. Riverine inputs of polybrominated diphenyl ethers from the Pearl River Delta (China) to the coastal ocean. Environ. Sci. Technol. 41, 6007-6013.

Han, J.L., Shen, H.T., Tie, X.W., Zhang, W.P., Zhu, G.N., Ren, Y.P., 2007. Polychlorinated dibenzo-p-dioxins/furans and polychlorinated biphenyls in fresh fishes from Qiantangjiang River, China. Chemosphere 68, 112-119.

He, J.Z., Robrock, K.R., Alvarez-Cohen, L., 2006a. Microbial reductive debromination of polybrominated diphenyl ethers (PBDEs). Environ. Sci. Technol. 40, 44294434.

He, M.C., Sun, Y., Li, X.R., Yang, Z.W., 2006b. Distribution patterns of nitrobenzenes and polychlorinated biphenyls in water, suspended particulate matter and sediment from mid- and down-stream of the Yellow River (China). Chemosphere 65, 365-374

Hui, Y.M., Zheng, M.H., Liu, Z.T., Gao, L.R., 2009. PCDD/Fs and dioxin-like PCBs in sediments from yellow estuary and yangtze estuary, China. Bull. Environ. Contam. Toxicol. 83, 614-619.

Kannan, K., Yun, S.H., Ostaszewski, A., McCabe, J.M., Mackenzie-Taylor, D. Taylor, A.B., 2008. Dioxin-like toxicity in the Saginaw River watershed: polychlorinated dibenzo-p-dioxins, dibenzofurans, and biphenyls in sediments and floodplain soils from the Saginaw and Shiawassee Rivers and Saginaw Bay, Michigan, USA. Arch. Environ. Contam. Toxicol. 54, 9-19.

Kannan, K., Maruya, K.A., Tanabe, S., 1997. Distribution and characterization of polychlorinated biphenyl congeners in soil and sediments from a superfund site contaminated with Aroclor 1268. Environ. Sci. Technol. 31, 1483-1488.

Lacorte, S., Raldua, D., Martinez, E., Navarro, A., Diez, S., Bayona, J.M., Barcelo, D. 2006. Pilot survey of a broad range of priority pollutants in sediment and fish from the Ebro river basin (NE Spain). Environ. Pollut. 140, 417-482.

Leung, A., Luksemburg, W.J., Wong, A.S., Wong, M.H., 2007. Spatial distribution of polybrominated diphenyl ethers and polychlorinated dibenzo-p-dioxins and dibenzofurans in soil and combusted residue at Guiyu, an electronic waste recycling site in southeast China. Environ. Sci. Technol. 41, 2730-2737.

Li, H.J., Lan, J., Li, G.L., Zhao, Z.S., Jiang, G.B., 2014. Distribution of polybrominated diphenyl ethers in the surface sediment of the East China Sea. Sci. Bull. 59, 379 387.

Li, H.H., Shang, H.T., Wang, P., Wang, Y.W., Zhang, H.D., Zhang, Q.H., Jiang, G.B., 2013 Occurrence and distribution of hexabromocyclododecane (HBCD) in sediments from seven major river drainage basins in China. J. Environ. Sci. China 25, 6976.

Liu, G.R., Zheng, M.H., 2013. Progress in the studies associated with formation and emission of unintentionally produced persistent organic pollutants. Sci. China Chem. 43, 265-278.

Liu, Y., Peng, P., Li, X., Zhang, S., Ren, M., 2008. Polychlorinated dibenzo-p-dioxins and dibenzofurans (PCDD/Fs) in water and suspended particulate matter from the Xijiang River, China. J. Hazard. Mater. 152, 40-47.

Liu, H.X., Zhang, Q.H., Wang, Y.W., Cai, Z.W., Jiang, G.B., 2007. Occurrence of polychlorinated dibenzo-p-dioxins, dibenzofurans and biphenyls pollution in sediments from the Haihe River and Dagu Drainage River in Tianjin City, China. Chemosphere 68, 1772-1778.

Liu, H.X., Zhang, Q.H., Cai, Z.W., Li, A., Wang, Y.W., Jiang, G.B., 2006. Separation of polybrominated diphenyl ethers, polychlorinated biphenyls, polychlorinated dibenzo-p-dioxins and dibenzo-furans in environmental samples using silica gel and florisil fractionation chromatography. Anal. Chim. Acta 557, 314-320.

Mai, B.X., Chen, S.J., Luo, X.J., Chen, L.G., Yang, Q.S., Sheng, G.Y., Peng, P.A., Fu, J.M., Zeng, E.Y., 2005. Distribution of polybrominated diphenyl ethers in sediments of the Pearl River delta and adjacent South China Sea. Environ. Sci. Technol. 39, 3521-3527.
Nie, Z., Tang, Z., Zhu, X., Yang, Y., Fu, H., Die, Q., Wang, Q., Huang, Q., 2013. Occurrence, possible sources, and temporal trends of polychlorinated dibenzo-pdioxins and dibenzofurans in water and sediment from the lower Yangtze River basin, Jiangsu and Shanghai areas of Eastern China. Environ. Sci. Pollut. Res. Int. 20, 8751-8762.

Nie, X.P., Lan, C.Y., Wei, T.L., Yang, Y.F., 2005. Distribution of polychlorinated biphenyls in the water, sediment and fish from the Pearl River Estuary, China. Mar. Pollut. Bull. 50, 537-546.

Okay, O.S., Karacik, B., Basak, S., Henkelmann, B., Bernhoft, Schramm, K.W., 2009 $\mathrm{PCB}$ and $\mathrm{PCDD} / \mathrm{Fs}$ in sediments and mussels of the Istanbul strait (Turkey). Chemosphere 76, 159-166.

Pan, X.H., Tang, J.H., Li, J., Guo, Z.G., Zhang, G., 2010a. Levels and distributions of PBDEs and PCBs in sediments of the Bohai Sea, North China. J. Environ. Monit. $12,1205-1376$

Pan, J., Yang, Y.L., Geng, C.Z., Yeung, L.W.Y., Cao, X.D., Dai, T.Y., 2010b. Polychlorinated biphenyls, polychlorinated dibenzo-p-dioxins and dibenzofurans in marine and lacustrine sediments from the Shandong Peninsula, China. J. Hazard. Mater. 176, 274-279.

Rappe, C., 1993. Source of exposure, environmental concentrations and exposure assessment of PCDDs and PCDFs. Chemosphere 27, 211-225.

Rayne, S., Ikonomou, M.G., Antcliffe, B., 2003. Rapidly increasing polybrominated diphenyl ether concentrations in the Columbia River system from 1992 to 2000. Environ. Sci. Technol. 37, 2847-2854.

Rodenburg, L.A., Guo, J., Du, S.Y., Cavallo, G.J., 2010. Evidence for Unique and Ubiquitous environmental sources of 3,3'-Dichlorobiphenyl (PCB 11). Environ. Sci. Technol. 44, 2816-2821.

Rowe, A.A., Totten, L.A., Xie, M., Fikslin, T.J., Eisenreich, S.J., 2007. Air-water exchange of polychlorinated biphenyls in the delaware river. Environ. Sci. Technol. $41,1152-1158$.

Ryoo, K.S., Ko, S.O., Hong, Y.P., Choi, J.H., Cho, S., Kim, Y., Bae, Y.J., 2005. Levels of PCDDs and PCDFs in Korean river sediments and their detection by biomarkers. Chemosphere 61, 323-331.

Shen, C., Chen, Y., Huang, S., Wang, Z., Yu, C., Qiao, M., Xu, Y., Setty, K., Zhang, J., Zhu, Y., Lin, Q., 2009a. Dioxin-like compounds in agricultural soils near e-waste recycling sites from Taizhou area, China: chemical and bioanalytical characterization. Environ. Int. 35, 50-55.

Shen, L., Gewurtz, S.B., Reiner, E.J., Macpherson, K.A., Kolic, T.M., Khurana, V., Helm, P.A., Howell, E.T., Burniston, D.A., Brindle, I.D., Marvin, C.H., 2009b. Occurrence and sources of polychlorinated dibenzo-p-dioxins, dibenzofurans and dioxin-like polychlorinated biphenyls in surficial sediments of Lakes Superior and Huron. Environ. Pollut. 157, 1210-1218.

Shen, L., Gewurtz, S.B., Reiner, E.J., Macpherson, K.A., Kolic, T.M., Helm, P.A., Brindle, I.D., Marvin, C.H., 2008. Patterns and sources of polychlorinated dibenzo-p-dioxins and polychlorinated dibenzofurans in surficial sediments of Lakes Erie and Ontario. Environ. Pollut. 156, 515-525.

Shen, M., Yu, Y.J., Zheng, G.J., Yu, H.X., Lam, P.K.S., Feng, J.F., Wei, Z.B., 2006. Polychlorinated biphenyls and polybrominated diphenyl ethers in surface sediments from the Yangtze River Delta. Mar. Pollut. Bull. 52, 1299-1304.

Song, W., Ford, J.C., Li, A., Mills, W.J., Buckley, D.R., Rockne, K.J., 2004. Polybrominated diphenyl ethers in the sediments of the great lakes 1. Lake superior. Environ. Sci. Technol. 38, 3286-3293.

Song, W., Li, A., Ford, J.C., Sturchio, N.C., Rockne, K.J., Buckley, D.R., Mills, W.J., 2005a. Polybrominated diphenyl ethers in the sediments of the great lakes. 2. Lakes Michigan and Huron. Environ. Sci. Technol. 39, 3474-3479.

Song, W., Ford, J.C., Li, A., Sturchio, N.C., Rockne, K.J., Buckley, D.R., Mills, W.J., 2005b. Polybrominated diphenyl ethers in the sediments of the great lakes. 3. Lakes Ontario and Erie. Environ. Sci. Technol. 39, 5600-5605.

Sun, Y.Z., Zhang, B., Gao, L.R., Liu, Z.T., Zheng, M.H., 2005. Polychlorinated dibenzop-dioxins and dibenzofurans in surface sediments from the estuary area of Yangtze River, People's Republic of China. Bull. Environ. Contam. Toxicol. 75 910-914.

US EPA, 1993. Interim Report on Data and Methods for Assessment of 2,3,7,8Tetrachlorodibenzo-p-Dioxin Risk to Aquatic Life and Associated Wildlife $\mathrm{EPA} / 600 / \mathrm{R} 93 / 055$.

Vives, I., Canuti, E., Castro-Jiménez, J., Christoph, E.H., Eisenreich, S.J., Hanke, G., Huber, T., Mariani, G., Mueller, A., Skejo, H., Umlauf, G., Wollgast, J., 2007. Occurrence of polychlorinated dibenzo-p-dioxins and dibenzofurans ( $\mathrm{PCDD} / \mathrm{Fs}$ ), polychlorinated biphenyls (PCBs) and polybrominated diphenyl ethers (PBDEs) in Lake Maggiore (Italy and Switzerland). J. Environ. Monit. 9, 589-598.

Wang, H.S., Du, J., Leung, H.M., Leung, A.O.W., Liang, P., Giesy, J.P., Wong, C.K.C., Wong, M.H., 2011. Distribution and source apportionments of polychlorinated biphenyls (PCBs) in mariculture sediments from the Pearl River Delta, South China. Mar. Pollut. Bull. 63, 516-522.

Wei, X., Leung, K.S., Wong, M.H., Giesy, J., Cai, Z.W., Wong, C.K.C., 2011. Assessment of risk of PCDD/Fs and dioxin-like PCBs in marine and freshwater fish in Pearl River Delta, China. Mar. Pollut. Bull. 63, 166-171.

Xing, Y., Lu, Y., Dawson, R.W., Shi, Y., Zhang, H., Wang, T., Liu, W., Ren, H., 2005. A spatial temporal assessment of pollution from PCBs in China. Chemosphere 60, 731-739.

Yang, Z.F., Shen, ZY, Gao, F, Tang, Z.W. Niu, J.F, 2009. Occurrence and possible sources of polychlorinated biphenyls in surface sediments from the Wuhan reach of the Yangtze River, China. Chemosphere 74, 1522-1530.

Zhang, H.J., Zhao, X.F., Ni, Y.W., Lu, X.B., Chen, J.P., Su, F., Zhao, L., Zhang, N., Zhang, X.P., 2010. PCDD/Fs and PCBs in sediments of the Liaohe River, China: levels, distribution, and possible sources. Chemosphere 79, 754-762. 
Zhang, S.K., Peng, P.A., Huang, W.L., Li, X.M., Zhang, G., 2009. PCDD/PCDF pollution in soils and sediments from the Pearl River Delta of China. Chemosphere 75, 1186-1195.

Zheng, G.J., Leung, A.O., Jiao, L.P., Wong, M.H., 2008. Polychlorinated dibenzo-pdioxins and dibenzofurans pollution in China: sources, environmental levels and potential human health impacts. Environ. Int. 34, 1050-1061.
Zheng, M.H., Chu, S.G., Sheng, G.Y., Min, Y.S., Bao, Z.C., Xu, X.B., 2001. Polychlorinated dibenzo-p-dioxins and dibenzofurans in surface sediments from the Pearl River Delta in China. Bull. Environ. Contam. Toxicol. 66, 504-507. 